\title{
'Blood doping' from Armstrong to prehabilitation: manipulation of blood to improve performance in athletes and physiological reserve in patients
}

\author{
James O. M. Plumb $1,2,3,4^{*}$, James M. Otto 5 and Michael P. W. Grocott ${ }^{1,2,3,4}$
}

\begin{abstract}
Haemoglobin is the blood's oxygen carrying pigment and is encapsulated in red blood corpuscles. The concentration of haemoglobin in blood is dependent on both its total mass in the circulation (tHb-mass) and the total plasma volume in which it is suspended. Aerobic capacity is defined as the maximum amount of oxygen that can be consumed by the body per unit time and is one measure of physical fitness. Observations in athletes who have undergone blood doping or manipulation have revealed a closer relationship between physical fitness (aerobic capacity) and total haemoglobin mass (tHb-mass) than with haemoglobin concentration ([Hb]). Anaemia is defined by the World Health Organisation (WHO) as a haemoglobin concentration of $<130 \mathrm{~g} / \mathrm{L}$ for men and $<120 \mathrm{~g} / \mathrm{L}$ for women. Perioperative anaemia is a common problem and is associated with increased mortality and morbidity following surgery. Aerobic capacity is also associated with outcome following major surgery, with less fit patients having a higher incidence of mortality and morbidity after surgery. Taken together, these observations suggest that targeted preoperative elevation of tHb-mass may raise aerobic capacity both directly and indirectly (by augmenting preoperative exercise initiatives- 'prehabilitation') and thus improve postoperative outcome. This notion in turn raises a number of questions. Which measure ([Hb] or tHb-mass) has the most value for the description of oxygen carrying capacity? Which measure has the most utility for targeting therapies to manipulate haemoglobin levels? Do the newer agents being used for blood manipulation (to increase tHb-mass) in elite sport have utility in the clinical environment? This review explores the literature relating to blood manipulation in elite sport as well as the relationship between perioperative anaemia, physical fitness and outcome following surgery, and suggests some avenues for exploring this area further.
\end{abstract}

Keywords: Blood doping, Blood manipulation, Anaemia, Perioperative, Surgery, Total haemoglobin mass, Autologous blood transfusion, Recombinant human erythropoietin $r \mathrm{HuEPO}$, Prehabilitation, Altitude, $\dot{\mathrm{V}} \mathrm{O}_{2 \text { max }}$ Cycling, Hypoxiainducible factors, Surgical outcomes

\section{Background}

Haemoglobin is the blood's oxygen carrying pigment. Erythropoietin is the hormone that stimulates human haemoglobin (and red blood corpuscle) synthesis. Its synthetic recombinant form ( $\mathrm{rHuEPO}$ ) is commonly

\footnotetext{
*Correspondence: j.plumb@soton.ac.uk

${ }^{4}$ Faculty of Medicine University of Southampton, Southampton General Hospital Mailpoint 801 South Academic Block, Tremona Road Southampton, Southampton SO16 6YD, UK

Full list of author information is available at the end of the article
}

used in clinical practice to augment haemoglobin levels, as is the use of agents that support haemoglobin synthesis (such as intravenous or oral iron, vitamin B12 or folic acid) when these are deficient. Hypoxia-inducible factor (HIF) is a transcriptional regulator that (amongst other effects) drives erythropoietin synthesis, and whereby enhances haemoglobin levels. The first recorded human blood transfusion took place in 1795 [1] and homologous blood transfusion is widely used in clinical practice for anaemic patients, including during the perioperative period. Some elite athletes have illegally tried to enhance 
their performance by increasing their haemoglobin levels and thereby increasing their oxygen carrying capacity via the so-called 'blood doping.' Such activities have often taken place prior to rigorous safety trials (being properly performed for medical benefit) that are a measure of the risks that such athletes are prepared to take to achieve success [2]. For example, there is evidence that the new HIF activators are being abused within elite sport [3-6].

Aerobic capacity is defined as the maximum amount of oxygen that can be consumed by the body per unit time and is one measure of the physical fitness. $\dot{\mathrm{VO}}_{2 \max }$ is classically defined as 'a plateau in oxygen uptake attained during maximal exercise despite further increases in exercise workload, thereby defining the limits of the cardiorespiratory system' [7]. However, many individuals do not reach a plateau in oxygen uptake despite maximum exertion, and the term $\dot{\mathrm{VO}}_{2 \text { peak }}$ is used instead, being the highest measured oxygen consumption during exercise, typically averaged over a $30 \mathrm{~s}$ period. $\mathrm{V}_{2}$ at anaerobic threshold is defined as the highest sustained intensity of exercise for which the measurement of oxygen uptake can account for the entire energy requirement.' An alternative definition is the exercise intensity at which lactate starts to accumulate in the blood stream' [8]. These oxygen uptake variables are in part dependent on the oxygen carrying capacity of the blood, which is in turn dependent on blood haemoglobin levels.

Anaemia is defined by the World Health Organisation (WHO) as a haemoglobin concentration of $<130 \mathrm{~g} / \mathrm{L}$ for men and $<120 \mathrm{~g} / \mathrm{L}$ for women [9]. Perioperative anaemia is common, with a quoted prevalence varying between 16 and $47 \%$ reported in different patient cohorts (see Table 1), and is associated with increased morbidity and mortality following surgery. Using data from the European Surgical Outcomes Study (EuSOS) [10], Baron et al found that the presence of moderate anaemia was associated with a higher likelihood of in-hospital mortality than when it was absent, after adjustment for co-morbidities and the severity of the surgery [odds ratio (OR) 1.99$95 \%$; confidence intervals (CI) 1.67-2.37] [11]. Both $\dot{\mathrm{V}}$ $\mathrm{O}_{2 \text { peak }}$ and $\dot{\mathrm{VO}}_{2 \mathrm{AT}}$ are positively correlated with outcome following major surgery: less physically fit patients having a higher incidence of mortality and morbidity after surgery. Much of the literature in this area is derived from studies reporting cardiopulmonary exercise testing (CPET) variables. The underlying hypothesis of these studies has been that patients with greater physiological reserve defined by CPET variables (most commonly $\dot{\mathrm{V}} \mathrm{O}_{2 \text { peak }}$ and $\dot{\mathrm{V}} \mathrm{O}_{2 \mathrm{AT}}$ ) are better able to withstand the physiological challenge of surgery. Given that the oxygen uptake variables $\dot{\mathrm{V}} \mathrm{O}_{2 \text { peak }}$ and $\dot{\mathrm{V}} \mathrm{O}_{2 \mathrm{AT}}$ are correlated with $[\mathrm{Hb}]$, it may be that some of the physical fitness-outcome relationship is mediated through haemoglobin related effects rather than cardiorespiratory function.

Prehabilitation is the process of enhancing functional capacity of the individual to enable him or her to withstand a subsequent stressor. This may be achieved through a single well-defined intervention (e.g. structured aerobic exercise programme) [20] or may encompass a package of smaller integrated steps leading to overall functional improvement, the so-called aggregation of marginal gains' [21-23]. Such interventions have a role in prehabilitation within clinical medicine in general, and before major surgery in particular. However, whilst the efficacy of such approaches in improving physical fitness is becoming clearer [20, 24], it is currently uncertain whether they will be effective in improving clinical outcomes in the perioperative setting. As we learn more about the relationship between physical fitness, defined by CPET-derived variables, and responses to prehabilitation in different patient groups, it may be that lessons learned from elite athletes could be applied to improving outcomes in patients around the time of surgery.

Table 1 Prevalence of preoperative anaemia

\begin{tabular}{llcc}
\hline Study & Cohort & Study population & Prevalence of anaemia (\%) \\
\hline Baron-BMJ 2014 [11] & Non-cardiac, non-neurological surgery & 46,539 & 28.7 \\
Sagger-Anesth Analg 2013 [12] & Non-cardiac surgery & 574,860 & 25.3 \\
Gupta Ann Surgery 2013 [13] & Patients over 65 elective vascular surgery & 31,857 & 47 \\
Musallam Lancet 2011 [14] & Non-cardiac surgery & 227,425 & 30.44 \\
Van Straten_Circulation 2009 [15] & Cardiac surgery & 10,025 & 16 \\
Beattie-Anaesthesiology 2009 [16] & Non-cardiac surgery & 7759 & 39.5 \\
Karkouti-Circulation 2008 [17] & Cardiac surgery & 3500 & 26 \\
Kulier-Circulation 2007 [18] & Cardiac surgery & 4804 & 28.1 male \\
Wu JAMA 2007 [19] & & & 35.9 female \\
\hline
\end{tabular}




\section{Measuring haemoglobin concentration vs. total haemoglobin mass}

Traditionally, the concentration of circulating haemoglobin $[\mathrm{Hb}]$ has been used as a clinical measure of the blood's oxygen carrying capacity. However, a low $[\mathrm{Hb}]$ may be due to a reduced amount of haemoglobin (absolute mass of circulating haemoglobin; tHb-mass) or an increased volume of dilution (plasma volume). Thus, $[\mathrm{Hb}]$ may be stable and tHb-mass low in the context of acute bleeding, $[\mathrm{Hb}]$ normal or elevated but tHb-mass low in the context of dehydration, or $[\mathrm{Hb}]$ low but tHb-mass normal or high in the context of excess plasma volume (fluid). Therefore, the use of $[\mathrm{Hb}]$ to define blood oxygen carrying capacity may be misleading under some circumstances.

tHb-mass represents the absolute mass of circulating haemoglobin in the body, the measured [ $\mathrm{Hb}$ ] being dependent upon tHb-mass and blood volume (BV) [sum of plasma volume (PV) and total red cell volume]. The proportion of oxygen carried in solution in plasma is trivial $(0.3 \mathrm{ml}$ per $100 \mathrm{ml}$ of plasma) under normal physiological conditions, whereas each gram of $\mathrm{Hb}$ binds up to $1.39 \mathrm{ml}$ of oxygen. Thus, tHb-mass is the principal determinant of total blood $\mathrm{O}_{2}$-carrying capacity and may provide additional information regarding the clinical status of patients than that provided by $[\mathrm{Hb}]$ alone.

It appears that tHb-mass is of greater utility in blood manipulation in elite athletes trying to improve sporting performance as it is more stable and predictable over time and also has a more direct correlation with performance. The question addressed by this review is whether $t \mathrm{Hb}$ mass, in comparison with haemoglobin concentration, is a more precise and accurate variable to guide targeting of haemoglobin manipulation, if the aim is to improve physiological reserve in patients in order to improve clinical outcomes. We also explore the techniques of blood manipulation in elite athletes and whether any of these techniques may be useful from a prehabilitation perspective within clinical medicine.

\section{Haemoglobin manipulation in sport}

Athletes and coaches are constantly pursuing legal means, such as training at altitude to augment oxygen carriage through an increase in $[\mathrm{Hb}]$ and thereby improving sea-level performance. However, recent revelations relating to high profile individuals within professional cycling, including Floyd Landis, Tyler Hamilton [25] and Lance Armstrong [26], have highlighted the illegal methods used by some athletes to improve performance, often in advance of the efforts of regulatory authorities to constrain them and of their adoption into clinical medicine [27]. It is legitimate to question whether such methods are safe (or at least fall within the broad margins of safety), if they are effective and if they could have wider applicability within clinical medicine.

Whilst a variety of agents have been used to manipulate haemoglobin levels (e.g. blood, recombinant human erythropoietin (rHuEPO), Continuous Erythropoietin Receptor Activator (CERA), hypoxia-inducible factor (HIFs) agents and possibly even 'gene doping' (although we do not yet have definitive evidence of this [28, 29]), the basic aim remains the same that increasing oxygen delivery $\left(\mathrm{DO}_{2}\right)$ through elevating haemoglobin levels will augment maximum oxygen uptake $\left(\dot{\mathrm{V}}_{2 \max }\right)$ and perhaps more importantly (for endurance events) increase the workload at which anaerobic threshold (AT) is reached. There is still debate around the factors that limit $\dot{\mathrm{VO}}_{2 \max }$, with candidate mechanisms including central control, cardiac limitation, mitochondrial utilisation and total oxygen delivery (the product of cardiac output and blood oxygen content). However, whilst there remains uncertainty about the dominant controlling factor, many authorities agree that in highly trained athletes, $\mathrm{DO}_{2}$ is a factor that contributes to $\dot{\mathrm{VO}}_{2 \max }$ limitation [30-32] and that $\dot{\mathrm{VO}}_{2 \max }$ is also, at least in part, dependent on a number of underlying genetic factors that are not amendable to modification through training [33]. Therefore, blood manipulation to augment $\mathrm{DO}_{2}$ has been seen as a logical, albeit illegal, approach to augmenting $\dot{\mathrm{V}} \mathrm{O}_{2 \max }$ and thereby improving athletic performance. It is notable in this regard that $\mathrm{tHb}$-mass displays a much stronger relationship with $\dot{\mathrm{VO}}_{2 \max }$ than does [Hb] $[34,35]$ and may therefore be a more useful marker of intervention efficacy. Here, the relationship between different physiological measures of physical fitness and performance merits consideration. Whilst the majority of sports research has focused on $\dot{\mathrm{V}}{ }_{2 \text { peak }}$ or $\dot{\mathrm{V}} \mathrm{O}_{2 \max }$ as the accepted gold standard indices of cardiorespiratory fitness, other variables may have an important role in determining performance, particularly in endurance events. As exercise increases above a threshold submaximal work rate, anaerobic respiration begins to contribute to Adenosine Triphosphate (ATP) production and this is both inefficient (relative to aerobic respiration) and unsustainable (due to progressive lactic acidosis). Therefore, when discussing performance, although a high total aerobic capacity $\left(\dot{\mathrm{V}} \mathrm{O}_{2 \text { peak }} / \dot{\mathrm{V}}\right.$ $\left.\mathrm{O}_{2 \max }\right)$ is important for success in endurance sports, submaximal indices of fitness, such as the lactate or anaerobic threshold (LT/AT) and exercise efficiency/economy, may also be critical determinants of performance. For example, two athletes with the same $\dot{\mathrm{V}}{ }_{2 \max }$ do not necessarily perform to the same level in an endurance performance test or race: the athlete with the higher $\dot{\mathrm{VO}}_{2 \mathrm{AT}}$ is likely to perform better. Furthermore, the efficiency or economy with which work is done relative to energy expenditure may be important. For example, Lucia et al 
showed that a range of $\dot{\mathrm{VO}}_{2 \max }$ levels amongst elite cyclists could be compensated for by differences in efficiency [36]. Whilst improvements to $\dot{\mathrm{V}}_{2 \max }$ are important, very few athletic competitions are performed at $\dot{\mathrm{V}}$ $\mathrm{O}_{2 \max }$ and it cannot therefore be assumed that performance will be enhanced to the same degree as $\dot{\mathrm{V}}_{2 \max }$ increases. Intriguingly, the premise that improvement in physiological variables (i.e. aerobic capacity) enhances athletic performance (i.e. races or gold medals won) has not been well investigated. Having said that, the effects of blood manipulation on a range of physiological variables, including to $\dot{\mathrm{V}} \mathrm{O}_{2 \mathrm{max} / \text { peak }}$ and $\dot{\mathrm{V}} \mathrm{O}_{2 \mathrm{AT}}$, are both of relevance for athletes and may have significance in clinical contexts [37].

\section{What is 'blood manipulation'/'blood doping'?}

The World Anti-Doping Agency (WADA) defines blood manipulation as the reintroduction of blood or blood products allogenic (homologous) or heterologous, the artificial enhancement of oxygen transportation or delivery and any form of intravascular manipulation of the blood or its components by physical or chemical means [3]. Blood doping is complex and rapidly evolving, as highlighted by the recent WADA amendments to the 2014 prohibited list consequent on the emergent use of Xenon and Argon as HIF activators. It was reported that Russian athletes used HIF activators at the 2014 winter Olympics in Sochi [3]. The earliest reports of 'blood doping' in the scientific literature date back to 1945-1947 $[38,39]$. The first alleged use in elite sport was in the 1960s, when a French four times Tour de France winner (1961-1964) was named as one of the first cyclists to use the technique [40]. The first reported use in athletics comes from around the time of the 1968 Mexico City Olympic Games.

It has been said, "Increasing the oxygen transport capacity of the exercising skeletal muscles, either by means of training or doping, is the most powerful tool for improving athletic performance in aerobic sports [41]". Below we will briefly outline some of the methods of blood manipulation used in sport.

\section{Autologous blood transfusion}

The link between the $\mathrm{O}_{2}$-carrying capacity of the blood and indices of exercise capacity such as $\dot{\mathrm{VO}}_{2 \max }$ has recently been reviewed elsewhere [34]. Haematocrit (Hct) is also known as packed cell volume (PCV) or erythrocyte volume (ECV) and is the volume percentage of red blood cells within the blood. There does not appear to be a simple linear correlation between haematocrit and increased $\dot{\mathrm{V}}_{2 \max }$. Brun et al showed that a "low" haematocrit (Hct) $(<40 \%)$ was associated with a higher aerobic capacity [42]. However, this must be interpreted with caution, as the lowest Hct was only 36.8 \% (i.e. not actually that low). It is probable that lower Hct levels, such as those seen in patients rather than athletes or healthy volunteers, would result in a reduced oxygen carrying capacity and therefore reduced $\dot{\mathrm{VO}}_{2 \max }$. By the 1970s, it was becoming well known that increasing tHbmass could increase $\dot{\mathrm{VO}}_{2 \max }$. It later became clear that other factors were also important, for example, changes in diastolic function and changes in blood volume (BV) [43].

A 1982 review documented all published studies comparing exercise testing variables pre-phlebotomy, and post transfusion, at that time. It is apparent from Table 2 that a significant increase in $[\mathrm{Hb}]$ was associated with an increase in $\dot{\mathrm{VO}}_{2 \max }$. The author concluded that at least 2 units of blood were needed with frozen blood being superior to refrigerated blood [44]. Of the 14 studies in Table 2, only 5 of them showed statistically significant improvements in $[\mathrm{Hb}]$ and $\dot{\mathrm{VO}}_{2 \max }$ post autologous transfusion [39, 45-48]. The results of studies failing to find such a relationship between $[\mathrm{Hb}]$ and exercise capacity may in part be explained by the small quantity of blood re-infused, insufficient time for the body to achieve equilibrium $[\mathrm{Hb}]$ after venesection, and inadequate storage of the RBCs [44].

In general, autologous blood transfusion seems to improve performance, but there are very few studies addressing this question directly. Improved 5-mile treadmill run times (mean improvement of $44 \mathrm{~s}$ ) with reduced self-reported perceived exertion after autologous blood transfusion were demonstrated by Williams et al [47]. Berglund et al demonstrated a significant fall in the race times of cross-country skiers when compared to matched controls pre- and post autologous blood transfusion [49]. Brien et al took 6 well-trained runners and improved their $10 \mathrm{~km}$ time by an average of $1 \mathrm{~min}$. Using a doubleblind cross-over design, each runner received a $400 \mathrm{ml}$ autologous transfusion of blood or saline repeated again 5 days apart with a $10 \mathrm{~km}$ race 5 days after each treatment. Five out of the 6 runners had faster race times after transfusion [50].

\section{Recombinant human erythropoietin: $r$ HuEPO}

There are more data available for rHuEPO and a number of studies have shown correlation between improved performance and rHuEPO use. In 1991, Ekblom et al showed an improved $\dot{\mathrm{VO}}_{2 \max }$ post rHuEPO injection in 15 volunteers [51]. Similar results were shown by Audran et al. Table 2 from this paper shows the increase in Hct and $[\mathrm{Hb}]$ from day 0 to day 24 and subsequent rise in $\dot{\mathrm{V}}$ $\mathrm{O}_{2 \max }$ with reduction in maximum heart rate [52]. Parisotto et al attempted to develop a blood profile to detect athletes who were abusing rHuEPO and were able to 
Table 2 Summary of studies of blood doping and exercise

\begin{tabular}{|c|c|c|c|c|c|c|c|}
\hline Authors & Date & $\begin{array}{l}\text { Storage tech- } \\
\text { nique }\end{array}$ & $\begin{array}{l}\text { Volume infused } \\
\text { (ml) }\end{array}$ & $\begin{array}{l}\text { Time of reinfusion } \\
\text { post phlebotomy }\end{array}$ & $\begin{array}{l}\text { Hb or Hct vs con- } \\
\text { trol }^{\mathbf{b}}(\%)\end{array}$ & $\begin{array}{l}\dot{\text { VOO }}{ }_{2 \max } \text { vs control } \\
(\%)\end{array}$ & $\begin{array}{l}\text { End capacityc vs } \\
\text { control }^{\text {b }}(\%)\end{array}$ \\
\hline Pace et al & 1947 & Fresh ${ }^{g}$ & 2000 & - & $+26^{d}$ & N.R & $+34.7^{d}$ \\
\hline Gullbring et al & 1960 & Refridg & 610 & 7 days & +0.7 & N.R & +3 \\
\hline Robinson et al & 1966 & Refridg & 1000 & 2 weeks & +4.8 & +1.4 & N.R \\
\hline \multirow[t]{2}{*}{ Ekblom et al } & 1972 & Refridg & 800 & 4 weeks & +2.1 & $+5.5^{\mathrm{e}}$ & $+15.6^{\mathrm{e}}$ \\
\hline & & Refridg & 1200 & 4 weeks & +1.3 & $+1.6^{\mathrm{e}}$ & $+25.1^{e}$ \\
\hline Von Rost et al & 1975 & Refridg & 900 & 3 weeks & +2.7 & $+9.0^{e}$ & $+37^{5}$ \\
\hline Bell et al & 1976 & Refridg & 500 & 3 weeks & +1.0 & $+5.6^{f}$ & +7.5 \\
\hline Ekblom et al & 1976 & Refridg & 800 & $\sim 5$ weeks & $+4.5^{\mathrm{e}}$ & $+8.0^{d}$ & N.R \\
\hline $\begin{array}{l}\text { Videman and } \\
\text { RytÖmaa }\end{array}$ & 1977 & Refridg & $4-600$ & 2-3 weeks & +2.6 & N.R & +3.8 \\
\hline Robertson et al & 1978 Abst & N.R & 1800 & NR & N.R. & $+12.8^{d}$ & $+15.6^{d}$ \\
\hline Williams et al & 1978 & Frozen & 460 & 3 weeks & +3.3 & N.R & +4.1 \\
\hline Cottrell & 1979 Abst & Frozen & 405 & 9 weeks & N.R. & $\sim+2.0^{f}$ & N.R \\
\hline Roberston et al & 1979 Abst & N.R & 800 & N.R. & $+15.8^{d}$ & $+30.5^{d}$ & $+13.1^{d}$ \\
\hline Buick et al & 1980 & Frozen & 900 & 7 weeks & $+11^{d}$ & $+5^{d}$ & $+35^{d}$ \\
\hline \multirow[t]{2}{*}{ Spriet et al } & 1980 Abst & Frozen & 800 & 11 weeks & $+7.9^{d}$ & $+3.9^{d}$ & N.R \\
\hline & & & 1200 & 12 weeks & $+10.7^{d}$ & $+6.6^{d}$ & N.R \\
\hline Williams et al & 1981 & Frozen & 920 & 7 weeks & $+7^{d}$ & N.R & $+2.5^{d}$ \\
\hline
\end{tabular}

Reproduced with permission from Wolters Kluwer Health [44]

$N R$ data not reported, Refridg refrigerated

a Whole blood or equivalent whole blood

b Control pre-phlebotomy measurement

c Endurance exercise capacity, physical work capacity or performance time

d Statistically significant $(P \leq 0.05)$

e No statistical analysis reported

$f$ Predicted from submaximal exercise heart rate

${ }^{g}$ Fresh homologous blood; all other studies used autologous blood

demonstrate a predictable blood profile post $\mathrm{rHuEPO}$ usage. They measured tHb-mass (using Burge and Skinner's method) and found a consistent increase in Hct, $[\mathrm{Hb}]$ and tHb-mass 3 weeks after rHuEPO administration, which persisted for 21 days. They also found a 6.3 and 6.9 \% increase in $\dot{\mathrm{V}} \mathrm{O}_{2 \max }$ compared to placebo. After a 4-week washout period, tHb-mass and $\dot{\mathrm{VO}}_{2 \max }$ had returned to baseline [53]. Birkeland et al showed in a double-blind placebo-controlled trial that injection of $5000 \mathrm{IU}$ of rHuEPO thrice weekly for 4 weeks improved $\dot{\mathrm{V}} \mathrm{O}_{2 \max }$ by $7 \%$. They found that Hct rose from a mean of 42.7-50.8 and peaked 1 day after rHuEPO was stopped. Haemoglobin concentration also increased in the rHuEPO group [54].

However, data supporting an improvement in performance following rHuEPO usage in athletes were still limited. Russell et al were the first to characterise the submaximal and maximal exercise adaptations to prolonged use of low dose rHuEPO. They compared 3 groups, (1) intravenous (i.v.) iron + rHuEPO, (2) oral iron + rHuEPO and (3) placebo. They performed exercise tests on a cycle ergometer at weeks $0,4,8$ and 12 . The relative increases in $\mathrm{VO}_{2 \max }$ at weeks 4,8 and 12 were $7.7,9.7$ and $4.5 \%$, respectively, for the rHuEPO + i.v. iron group; 6.0, 4.7 and $3.1 \%$ for the oral iron + rHuEPO group; and -0.5 , -0.1 and $-1.0 \%$ for the placebo group [55].

In 2007, Thomsen et al stated that "Although the positive effect of rHuEPO treatment on $\dot{\mathrm{VO}}_{2 \max }$ is clearly established, it remains unknown as to what its impact is on endurance performance". They investigated the effect of $\mathrm{rHuEPO}$ on $\dot{\mathrm{VO}}_{2 \max }$ and time to exhaustion during cycle ergometry in healthy volunteers. rHuEPO significantly increased $\dot{\mathrm{V}} \mathrm{O}_{2 \max }$ by 9.1 and $8.1 \%$ in week 4 and 11 , respectively, with no changes in the placebo group [37].

\section{Emerging strategies}

The range of interventions aimed at increasing tHb-mass, both in development and currently available, is large and has been extensively reviewed elsewhere $[2,4,6,56]$.

Towards the end of the 1990s, interest had grown within clinical medicine and the sporting world in using 
artificial oxygen carriers and perfluorocarbon emulsions [57]. However, neither has been adopted in either setting, probably due to well-recognised adverse effects and ease of detection [58].

HIF stabilisers/activators are compounds that act by mimicking hypoxia and thereby stimulating EPO synthesis via the HIF pathway. When the partial pressure of oxygen is low, HIF1 $\alpha$ undergoes a stabilisation process, which leads to gene transcription, including that of the erythropoietin gene [59,60]. HIF stabilisers/activators are oral compounds, which are potentially advantageous as they are simply administered and are less immunogenic than erythrocyte-stimulating agents such as rHuEPO. The number of agents available is beyond the scope of this review and has recently been summarised elsewhere [2]. There is already clear evidence of their abuse within elite sport $[3-5,56]$. Cobalt is one such agent, which has adverse effects including heart, liver, kidney and thyroid toxicity as well as cancer promotion [61]. There is evidence of cobalt being abused in horse racing [62]. Xenon and argon are also both HIF activators and have both been reportedly used as performanceenhancing agents in the recent years $[3,63]$.

Gene therapy is also theoretically possible, but some early reports highlighting significant safety concerns including life-threatening red cell aplasia and extreme erythrocytosis have probably limited its use [64]. There are also EPO-mimetic peptides such as Peginesatide that are not currently in production but are nevertheless candidates for abuse [2].

\section{Harms: what are the downsides?}

Not only is blood manipulation/doping illegal, but also many of the agents used may pose health risks to the athlete. Despite this, some athletes are apparently prepared to accept such risks to increase their chances of success. As has already been noted, manipulation of haemoglobin may be associated with a variety of adverse effects including, for example, hyper-viscosity from $\mathrm{rHuEPO}$ and the toxic effect of cobalt. The risks associated with blood transfusion are summarised in Table 3.

\section{Haemoglobin manipulation in the clinical setting}

Blood manipulation occurs commonly in clinical practice. In the UK, approximately 8000 units of blood are transfused each day [69] including homologous transfusion and transfusion of blood salvaged during major surgery. The level of anaemia that mandates blood transfusion is not well defined in all perioperative settings $[67,70-74]$ and there has been a shift over the last two decades towards more conservative transfusion strategies, particularly within intensive care $[75,76]$. Whilst the association of anaemia with adverse outcome is well

\begin{tabular}{|c|c|}
\hline Theoretical & Demonstrated \\
\hline \multirow{13}{*}{$\begin{array}{l}\text { Age of stored blood } \\
\text { may affect its efficacy; } \\
\text { the so-called 'storage } \\
\text { lesion'[65] }\end{array}$} & Transfer of infectious diseases [40] \\
\hline & Transfusion reactions/anaphylaxis \\
\hline & Increase in colorectal cancer recurrence [66] \\
\hline & Phlebitis [40] \\
\hline & Septicaemia [40] \\
\hline & Graft versus host disease (GvHD) \\
\hline & $\begin{array}{l}\text { Transfusion-related immunomodulation (TRIM) } \\
{[67,68]}\end{array}$ \\
\hline & Hyper-viscosity PE and DVT [40] \\
\hline & Air embolism [40] \\
\hline & Transfusion-related acute lung injury (TRALI) \\
\hline & Risk of wrong blood (storage problems) [25] \\
\hline & Detraining effect [40] \\
\hline & Illegal practice to blood dope $[25,26]$ \\
\hline
\end{tabular}

recognised, uncertainty remains as to whether this relationship is causal and about when and how to intervene in the perioperative period. It is unclear whether anaemia per se causes increased morbidity/mortality or whether anaemia is associated with other (perhaps unidentified) pathology, which is the cause of the adverse outcomes. Whilst the study by Baron et al suggests that anaemia alone (once all co-morbidities are corrected for) is associated with an increased mortality in perioperative patients [11], residual confounding cannot be excluded due to the observational design of this study. Of note, measures to correct anaemia (including transfusion) seem ineffective at reducing the incidence of adverse outcome. This may be because anaemia is not the cause of the underlying pathology, in which case correcting anaemia would not be expected to improve outcome, or alternatively that adverse consequences of the interventions used (such as blood transfusion) outweigh the benefits of correcting anaemia. It is commonly hypothesised that much of the morbidity associated with a more liberal transfusion strategy is due to the adverse effects of homologous stored blood rather than the increased oxygen carrying capacity actually being ineffective. The on-going evolution of preparation techniques for transfused blood is likely continuing to alter the risk-benefit ratio for different transfusion strategies. Amongst the multiple reasons for potential harm from transfused blood (see Table 3), age of the blood is an area that has recently been investigated [77]; however, no significant differences were found with regard to 90-day mortality between a fresh blood 
group (6.1 \pm 4.9 days) and when compared with standard blood (22.0 \pm 8.4 days) [77]. A recent analysis of the FOCUS study comparing a liberal and restrictive strategy in hip fracture patients found no difference in 3-year mortality [70]. The balance between the theoretical benefits of augmenting $\mathrm{DO}_{2}$ and the harms of transfusion remains unclear: "Blood transfusion is like a marriage: It should not be entered into lightly, unadvisedly, or wantonly, or more often than is absolutely necessary" [78].

Two large observational datasets in non-cardiac surgery have shown that anaemic patients spend more time in intensive care, suffer more complications, stay in hospital longer, consume greater hospital resource and are more likely to die $[11,14]$. The same pattern is also reflected in data from cardiac surgical practice $[17,79]$. NHS England has issued guidance on the management of patients who present for elective surgery. The poor outcome associated with anaemia has led to the recommendation that these patients have their surgery delayed until treatment of their anaemia has occurred [80].

Whilst anaemia is clearly important, some authors have questioned its reliability as an independent marker of ill health as it may often be linked to an underlying acute or chronic disease that may yet be undiagnosed. Interestingly, Baron et al accounted for this: after adjusting for co-morbidities and severity of the surgery, patients with moderate anaemia had a higher in-hospital mortality [odds ratio 1.99 (95\% confidence interval 1.67-2.37)] [11]. Despite this, there is currently no convincing evidence that treating the absolute value of $[\mathrm{Hb}]$ improves outcome.

Importantly, the majority of studies in perioperative transfusion have examined the 'very anaemic' and attempted to move them to the 'slightly less anaemic'. Little work has been done to manipulate 'normal physiology' to target supra-optimal $\mathrm{DO}_{2}$ values (through $\mathrm{Hb}$ augmentation) in this population. Manipulation of tHb-mass, in contrast to $[\mathrm{Hb}]$, in patients who are about to undergo a physiological challenge, may improve their resilience to such an insult. Equating 'performance' gains by elite athletes to the ability of patients to survive surgery involves a substantial conceptual leap, but recent preliminary work has shown that transfusion can improve exercise variables in anaemic patients [81]. It remains uncertain whether clinical outcomes will alter alongside changes in tHb-mass and whether the closer relationship between tHb-mass (compared with $[\mathrm{Hb}]$ ) and performance in the athletic context, will be mirrored for patient outcomes in the clinical context. Indeed it may be that the metabolic cost of modern surgery has been overestimated, thus allowing for an adequate $\mathrm{DO} 2$ at 'low' $\mathrm{O}_{2}$ carrying states. The recent POM-O study was a randomised controlled trial of patients undergoing major elective surgery.
Patients were randomised to a postoperative protocol (fluid, with and without dobutamine) targeted to achieve their individual preoperative oxygen delivery value (goal-directed therapy) or standardised care (control). Maintaining $\mathrm{DO}_{2}$ appeared to be the important factor regardless of whether patients were in the goal-directed therapy group (fluids and dobutamine) or the usual care group [82].

\section{Prehabilitation}

Interest in prehabilitation has grown off the back of the success of enhanced recovery programmes (ERPs). ERPs were set up to try improving surgical outcomes by implementing care pathways. These pathways did not focus on discovering new knowledge but placed importance on integrating the best evidence into practice. It has been shown that exercise testing in patients before surgery is feasible and that physiological gains can be made in only short periods of time [12, 83, 84], although the clinical benefits remain uncertain [24]. CPET may play a role in guiding prehabilitation [85].

In a recent study, AT improved by a mean difference of $1.2 \mathrm{ml} \mathrm{kg}^{-1} \mathrm{~min}^{-1}$ in anaemic patients who had CPET pre- and post the transfusion of autologous blood [81]. The clinical effects of an increase in $\dot{\mathrm{VO}}_{2}$ at the AT of around $1 \mathrm{ml} \mathrm{kg}^{-1} \mathrm{~min}^{-1}$ are uncertain and this was a small single-centre study (with consequent elevated risk of bias). However, the results were consistent with a study in thalassemic patients, showing improved exercise duration and $\dot{\mathrm{V}} \mathrm{O}_{2 \text { peak }}$ [86]. Pilot et al showed that autologous transfusion following hip arthroplasty improved early postoperative exercise testing variables, but this effect was equivocal by day 23. However, this study was not randomised and is therefore subject to risk of both confounding and bias [87]. This area needs further research. There is an on-going study looking at intravenous iron infusion in major abdominal surgery [88]. The transfusion trigger in major elective surgery remains unknown, particularly with regard to outcomes such as ability to mobilise postoperatively [89]. Within the hip fracture population, postoperative anaemia is associated with increased length of stay, reduced ambulation and reduced functional independence [90]. However, evidence is lacking for a liberal transfusion strategy in non-cardiac surgery $([\mathrm{Hb}] 80-100 \mathrm{~g} / \mathrm{L})$ and this is consistent with the literature in critically unwell patients with septic shock [75].

The effects of prehabilitation training on the mitochondrial architecture, redox state and muscle capillary network remain unstudied in surgical patients and the additional effect of augmenting tHb-mass is also unknown. Training effects are of course different from the effects of blood manipulation and optimising the 
most critical steps in mitochondrial oxygen transport by training may be superior to using rHuEPO to enhance gene expression and induce angiogenesis; however, this remains to be elucidated. Exercise modifies mitochondrial biogenesis, not only by upregulating antioxidant enzymes but also by increasing mitochondrial number, thereby allowing for a lower level of respiratory activity for the same degree of ATP generation [91, 92]. Interestingly, Jacobs et al found that improvement in exercise performance after six sessions of high intensity training (HIT) over the span of 2 weeks was primarily attributed to enhanced oxidative potential in the skeletal muscle with no measurable effect on tHb-mass [91].

It may be that for some patients $\mathrm{DO}_{2}$ may be critical to $\mathrm{VO}_{2}$ and survival, whereas in another group of patients, anaemia, fitness levels and $\mathrm{DO}_{2}$ are part of a broader pattern of resilience. The biological pathways whereby regular physical activity might confer resilience include: (1) serving as a buffer against stress and stress-related disorders/chronic diseases, (2) optimising neuroendocrine and physiological responses to physical and psychosocial stressors, (3) promoting an anti-inflammatory state and (4) enhancing neuroplasticity and growth factor expression [93].

Are we then aiming for the total package of broader gains from 'fitness' or can we just look at specific targets such as tHb-mass? Whilst the complex biological mechanisms that relate 'fitness' to resilience remain opaque, it could be postulated that differences or gains (from targeted therapy or intervention) seen by patients on the CPET bike are simply a result of the other unmeasured markers of physical fitness. In the 1990s-2000s, when professional cycling had a widespread doping problem, highly trained elite athletes were experiencing significant gains over and above the increased gains in fitness from simply having a greater $\mathrm{DO}_{2}$ (primarily from doping, giving them a far greater tHb-mass). It is likely that patients would benefit from increased fitness levels and pilot data suggest that physical training does indeed return fitness levels back to baseline after a physiological insult such as chemotherapy [20]. Whether increasing tHb-mass offers benefit to all patients, or only those in whom it is initially subnormal remains to be elucidated.

\section{Future directions}

We know that the manipulation of tHb-mass is possible via a number of strategies. There is good evidence that CPET variables can be improved in line with gains in tHb-mass in athletes. We also know that fitness relates to outcome following surgery. What is not known is if the same relationship between physical fitness (CPET variables) and tHb-mass exists in patients who are awaiting major surgery or critically ill in hospital. The measurement of tHb-mass and correlation to CPET variables has not been studied within clinical medicine. It is also not clear which method would be best to manipulate tHb-mass in patients and what would represent the 'optimal' tHb-mass in each individual, balancing the risks of an increased tHb-mass with the theoretical benefits of improved oxygen delivery. We hypothesise that tHb-mass is a more accurate variable to guide and quantify potential intervention than $[\mathrm{Hb}]$ as it is relatively more stable [94-97] and is not affected by changes in plasma volume which may vary greatly in the perioperative period.

Informative studies might focus on measuring tHbmass in different patient groups and quantifying the relationship with CPET variables. Initial work to establish safety margins for different levels of haemoglobin mass in the perioperative period and the safest method for achieving them would be valuable. Preliminary studies to establish the strength of relationship between tHb-mass and outcome in comparison with that of $[\mathrm{Hb}]$ would also be of value. It may then be justifiable to explore whether manipulation of tHb-mass, rather than $[\mathrm{Hb}]$, has a positive effect on surgical outcomes in adequately powered randomised controlled trials.

It is not known what an increased tHb-mass does to mitochondrial function or if the benefits of training that come from a high intensity programme, in terms of improved mitochondrial content and function [91], can be augmented by boosting tHb-mass via rHuEPO, autologous blood transfusion or iron therapy. The ergogenic effects of EPO independent of its effect on boosting tHb-mass warrant further study and it is likely that there is a complex interplay between erythropoietin concentrations, reticulocyte migration and gene expression that may affect CPET variables and possibly outcome.

\section{Conclusions}

In performance sport, blood doping continues to be a problem. Novel agents are continually being developed and the regulatory bodies struggle to catch up with the dopers. The success of such strategies raises the question as to whether some of these approaches may have utility in clinical practice.

In particular, the closer relationship between $\mathrm{tHb}$-mass (rather than $[\mathrm{Hb}]$ ) and $\mathrm{VO}_{2 \max }$ raises the question as to whether we should be targeting this variable with blood manipulation techniques in the clinical setting.

The recognised association between low levels of physical fitness and adverse clinical outcomes in the perioperative context offer a specific clinical setting in which it may be valuable to address these questions. Furthermore, preoperative exercise training interventions (prehabilitation) may be optimised by such an approach. 
Observational studies clarifying the relationship between $\mathrm{tHb}$-mass and physical fitness and clinical outcomes in patients are required before interventional studies using this variable to target blood manipulation strategies are justified. The newer agents being used for blood manipulation in elite sport may have utility in this respect in the clinical environment.

\section{Health warning}

Blood doping/boosting or manipulation of the blood in anyway is inherently dangerous and can result in death. The authors strongly discourage anyone from undertaking any form of blood manipulation except under the close supervision of a trained medical specialist as part of a research trial or as a planned medical intervention for ill health.

The authors would also advocate that anyone manipulating their blood within the rules of the World Anti-Doping Authorities (WADA) such as by altitude training or artificial hypobaric environment usage do so under the close supervision of a medical professional experienced in the manipulation of haemoglobin. https://www.wada-ama.org/.

\begin{abstract}
Abbreviations
AT: anaerobic threshold; BV: blood volume; CERA: Continuous Erythropoietin Receptor Activator; CPET: cardiopulmonary exercise testing; EPO: erythropoietin; ECV: erythrocyte volume; [Hb]: haemoglobin concentration; Hct: haematocrit; HIFs: hypoxia-inducible factors; LT: lactate threshold; PCV: packed cell volume; RCV: red cell volume; rHuEPO: recombinant human erythropoietin; tHb-mass: total haemoglobin mass; TRIM: transfusion-related immunomodulation; $\dot{V}_{2 \text { max }}$ : maximum oxygen uptake; $\dot{\mathrm{V}} \mathrm{O}_{2 \text { peak: }}$ : peak oxygen uptake; WADA: World Anti-Doping Agency.
\end{abstract}

\section{Authors' contributions}

JP conceived the review, coordinated it and helped to draft the manuscript. JO helped drafting the manuscript. MG helped with drafting and reviewed the manuscript. All authors read and approved the final manuscript.

\section{Author details \\ ${ }^{1}$ Anaesthesia and Critical Care Research Unit, University Hospital South- ampton NHS Foundation Trust, Southampton, UK. ${ }^{2}$ Integrative Physiology and Critical IIlness Group, Clinical and Experimental Sciences, Faculty of Medi- cine, University of Southampton, University Road, Southampton, UK. ${ }^{3}$ Critical Care Research Area, Southampton NIHR Respiratory Biomedical Research Unit, Southampton, UK. ${ }^{4}$ Faculty of Medicine University of Southampton, Southampton General Hospital Mailpoint 801 South Academic Block, Tremona Road Southampton, Southampton SO16 6YD, UK. ${ }^{5}$ Division of Surgery and Interventional Science c/o, Institute of Sport, Exercise and Health (ISEH), 170 Tottenham Court Road, London, UK.}

\section{Competing interests}

The authors declare that they have no competing interests.

Received: 27 July 2015 Accepted: 12 February 2016

Published online: 29 February 2016

\section{References}

1. Highlights of transfusion medicine history. http://www.aabb.org/tm/ Pages/highlights.aspx. Accessed 27 Nov 2015.
2. Thevis M, Schänzer W. Analytical approaches for the detection of emerging therapeutics and non-approved drugs in human doping controls. J Pharm Biomed Anal. 2014;101:66-83.

3. World Anti-Doping Agency-2016 List of prohibited substances and methods http://www.list.wada-ama.org/. Accessed 01 Feb 2016.

4. Thevis M, Schänzer W. Illicit organogenesis: methods and substances of doping and manipulation. Organogenesis. 2008;4:264-71.

5. Thevis M, Piper T, Geyer H, Schaefer MS, Schneemann J, Kienbaum P, et al. Urine analysis concerning xenon for doping control purposes. Rapid Commun Mass Spectrom. 2015;29:61-6.

6. Beuck S, Schänzer W, Thevis M. Hypoxia-inducible factor stabilizers and other small-molecule erythropoiesis-stimulating agents in current and preventive doping analysis. Drug Test Anal. 2012;4:830-45.

7. Bassett DR, Howley ET. Limiting factors for maximum oxygen uptake and determinants of endurance performance. Med Sci Sports Exerc. 2000;32:70-84.

8. Beaver WL, Wasserman K, Whipp BJ. A new method for detecting anaerobic threshold by gas exchange. J Appl Physiol. 1985;1986(60):2020-7.

9. Organization WH. Worldwide prevalence of anaemia 1993-2005: WHO global database on anaemia 2008. http://apps.who.int/iris/bitstr eam/10665/43894/1/9789241596657_eng.pdf. Accessed 04 Feb 2016.

10. Pearse RM, Rhodes A, Moreno R, Pelosi P, Spies C, Vallet B, et al. EuSOS: European surgical outcomes study. Eur J Anaesthesiol. 2011;28:454-6.

11. Baron DM, Hochrieser H, Posch M, Metnitz B, Rhodes A, Moreno RP, et al. European Society of Anaesthesiology: preoperative anaemia is associated with poor clinical outcome in non-cardiac surgery patients. $\mathrm{Br} J$ Anaesth. 2014;113:416-23

12. Saager L, Turan A, Reynolds LF, Dalton JE, Mascha EJ, Kurz A. The association between preoperative anemia and 30-day mortality and morbidity in noncardiac surgical patients. Anesth Analg. 2013;117:909-15.

13. Gupta PK, Sundaram A, Mactaggart JN, Johanning JM, Gupta H, Fang X, et al. Preoperative anemia is an independent predictor of postoperative mortality and adverse cardiac events in elderly patients undergoing elective vascular operations. Ann Surg. 2013;258:1096-102.

14. Musallam KM, Tamim HM, Richards T, Spahn DR, Rosendaal FR, Habbal A, et al. Preoperative anaemia and postoperative outcomes in non-cardiac surgery: a retrospective cohort study. Lancet. 2011;378:1396-407.

15. van Straten AH, Hamad MA, van Zundert AJ, Martens EJ, Schönberger JP, de Wolf AM. Preoperative hemoglobin level as a predictor of survival after coronary artery bypass grafting: a comparison with the matched general population. Circulation. 2009;120:118-25.

16. Beattie WS, Karkouti K, Wijeysundera DN, Tait G. Risk associated with preoperative anemia in noncardiac surgery: a single-center cohort study. Anesthesiology. 2009;110:574-81.

17. Karkouti K, Wijeysundera DN, Beattie WS. Reducing Bleeding in Cardiac Surgery (RBC) Investigators: risk associated with preoperative anemia in cardiac surgery: a multicenter cohort study. Circulation. 2008;117:478-84.

18. Kulier A, Levin J, Moser R, Rumpold-Seitlinger G, Tudor IC, Snyder-Ramos SA, et al. Ischemia Research and Education Foundation: impact of preoperative anemia on outcome in patients undergoing coronary artery bypass graft surgery. Circulation. 2007;116:471-9.

19. Wu WC, Schifftner TL, Henderson WG, Eaton CB, Poses RM, Uttley G, et al. Preoperative hematocrit levels and postoperative outcomes in older patients undergoing noncardiac surgery. JAMA. 2007;297:2481-8.

20. West MA, Loughney L, Lythgoe D, Barben CP, Sripadam R, Kemp GJ, et al. Effect of prehabilitation on objectively measured physical fitness after neoadjuvant treatment in preoperative rectal cancer patients: a blinded interventional pilot study. Br J Anaesth. 2015;114(2):244-51.

21. Smith J, Meng ZW, Lockyer R, Dudderidge T, McGrath J, Hayes M, et al. Evolution of the Southampton Enhanced Recovery Programme for radical cystectomy and the aggregation of marginal gains. BJU Int. 2014;114:375-83.

22. Baldini G, Fawcett WJ. Anesthesia for colorectal surgery. Anesthesiol Clin. 2015;33:93-123.

23. Carney A, Dickinson M. Anesthesia for esophagectomy. Anesthesiol Clin. 2015;33:143-63.

24. O'Doherty AF, West M, Jack S, Grocott MP. Preoperative aerobic exercise training in elective intra-cavity surgery: a systematic review. $\mathrm{Br} J$ Anaesth. 2013;110:679-89. 
25. Hamilton T, Coyle D. The secret race: inside the hidden world of the Tour de France: doping, cover-ups, and winning at all costs. A Corgi book: 9780552169172, UK: Bantham Press. 2012. ISBN 055216917X.

26. Walsh David. Seven deadly sins: my pursuit of Lance Armstrong. Hardback edition. UK: Simon and Schuster; 2012. ASIN: B00HTJVMD4.

27. Morkeberg J, Saltin B, Belhage B, Damsgaard R. Blood profiles in elite cross-country skiers: a 6-year follow-up. Scand J Med Sci Sports. 2009;19:198-205.

28. Gronde TVD, de Hon O, Haisma HJ, Pieters T. Gene doping: an overview and current implications for athletes. Bri J Sport Med. 2013;47:670-8.

29. Fischetto $G$, Bermon S. From gene engineering to gene modulation and manipulation: can we prevent or detect gene doping in sports? Sports Med. 2013:43:965-77.

30. Wagner PD. New ideas on limitations to VO2max. Exerc Sport Sci Rev. 2000;28:10-4

31. Saltin B, Calbet JAL. Point: in health and in a normoxic environment, $\mathrm{VO}_{2}$ max is limited primarily by cardiac output and locomotor muscle blood flow. J Appl Physiol. 2006;100:744-8.

32. Joyner MJ. VO $\mathrm{O}_{2 \mathrm{MA}}$, blood doping, and erythropoietin. Brit J Sport Med. 2003;37:190-1.

33. Grimaldi KA, Paoli A, Smith GJ. Personal genetics: sports utility vehicle? Recent Pat DNA Gene Seq. 2012;6:209-15.

34. Otto JM, Montgomery HE, Richards T. Haemoglobin concentration and mass as determinants of exercise performance and of surgical outcome. Extr Physiol Med. 2013;2:33.

35. Saunders PU, Garvican-Lewis LA, Schmidt WF, Gore CJ. Relationship between changes in haemoglobin mass and maximal oxygen uptake after hypoxic exposure. Brit J Sport Med. 2013;47:i26-30.

36. Lucía A, Hoyos J, Pérez M, Santalla A, Chicharro JL. Inverse relationship between VO2max and economy/efficiency in world-class cyclists. Med Sci Sports Exerc. 2002;34:2079-84.

37. Thomsen JJ, Rentsch RL, Robach P, Calbet JA, Boushel R, Rasmussen P, et al. Prolonged administration of recombinant human erythropoietin increases submaximal performance more than maximal aerobic capacity. Eur J Appl Physiol. 2007;101:481-6.

38. Pace N, Consolazio WV, Lozner EL. The effect of transfusions of red blood cells on the hypoxia tolerance of normal men. Science. 1945;102:589-91.

39. Pace N, Lozner EL, Consolazio WV, Pitts GC, Pecora LJ. The increase in hypoxia tolerance of normal men accompanying the polycythemia induced by transfusion of erythrocytes. Am J Physiol. 1947;148:152-63.

40. Leigh-Smith S. Blood boosting. Brit J Sport Med. 2004;38:99-101.

41. Segura J, Lundby C. Blood doping: potential of blood and urine sampling to detect autologous transfusion. Br J Sports Med. 2014;48:837-41.

42. Brun JF, Bouchahda C, Chaze D, Benhaddad AA, Micallef JP, Mercier J. The paradox of hematocrit in exercise physiology: which is the "normal" range from an hemorheologist's viewpoint? Clin Hemorheol Microcirc. 2000;22:287-303.

43. Gledhill N, Warburton D, Jamnik V. Haemoglobin, blood volume, cardiac function, and aerobic power. Can J Appl Physiol. 1999;24:54-65.

44. Gledhill N. Blood doping and related issues: a brief review. Med Sci Sports Exerc. 1982;14:183-9.

45. Buick FJ, Gledhill N, Froese AB, Spriet L, Meyers EC. Effect of induced erythrocythemia on aerobic work capacity. J Appl Physiol Respir Environ Exerc Physiol. 1980;48:636-42.

46. Robertson RJ, Gilcher R, Metz KF, Casperson CJ, Allison TG, Abbott RA, Skrinar GS, Krause JR, Nixon PA. Hemoglobin concentration and aerobic work capacity in women following induced erythrocythemia. J Appl Physiol Respir Environ Exerc Physiol. 1984;57:568-75.

47. Williams MH, Wesseldine S, Somma T, Schuster R. The effect of induced erythrocythemia upon 5-mile treadmill run time. Med Sci Sports Exerc. 1981;13:169-75

48. Spriet LL, Gledhill N, Froese AB, Wilkes DL, Meyers EC. The effect of induced erythrocythemia on central circulation and oxygen- transport during maximal exercise. Med Sci Sports Exerc. 1980;12:122-3.

49. Berglund $B$, Hemmingson P. Effect of reinfusion of autologous blood on exercise performance in cross-country skiers. Int J Sports Med. 1987;8:231-3.

50. Brien AJ, Simon TL. The effects of red blood cell infusion on $10-\mathrm{km}$ race time. JAMA. 1987;257:2761-5.

51. Ekblom B, Berglund B. Effect of erythropoietin administration on mammal aerobic power. Scand J Med Sci Spor. 1991;1:88-93.
52. Audran M, Gareau R, Matecki S, Durand F, Chenard C, Sicart MT, et al. Effects of erythropoietin administration in training athletes and possible indirect detection in doping control. Med Sci Sports Exerc. 1999;31:639-45.

53. Parisotto R, Gore CJ, Emslie KR, Ashenden MJ, Brugnara C, Howe C, et al. A novel method utilising markers of altered erythropoiesis for the detection of recombinant human erythropoietin abuse in athletes. Haematologica. 2000;85:564-72.

54. Birkeland Kl, Stray-Gundersen J, Hemmersbach P, Hallen J, Haug E, Bahr R. Effect of rhEPO administration on serum levels of sTfR and cycling performance. Med Sci Sports Exerc. 2000;32:1238-43.

55. Russell G, Gore CJ, Ashenden MJ, Parisotto R, Hahn AG. Effects of prolonged low doses of recombinant human erythropoietin during submaximal and maximal exercise. Eur J Appl Physiol. 2002;86:442-9.

56. Beuck S, Bornatsch W, Lagojda A, Schänzer W, Thevis M. Development of liquid chromatography-tandem mass spectrometry-based analytical assays for the determination of HIF stabilizers in preventive doping research. Drug Test Anal. 2011;3:756-70.

57. Farrar D, Grocott M. Intravenous artificial oxygen carriers. Hosp Med. 2003;64:352-6.

58. Schumacher YO, Schmid A, Dinkelmann S, Berg A, Northoff H. Artificial oxygen carriers-the new doping threat in endurance sport? Int J Sports Med. 2001;22:566-71.

59. Déry MA, Michaud MD, Richard DE. Hypoxia-inducible factor 1: regulation by hypoxic and non-hypoxic activators. Int J Biochem Cell Biol. 2005;37:535-40.

60. Lippi G, Franchini M, Guidi GC. Cobalt chloride administration in athletes: a new perspective in blood doping? Br J Sports Med. 2005;39:872-3.

61. Lippi G, Franchini M, Guidi GC. Blood doping by cobalt. Should we measure cobalt in athletes? J Occup Med Toxicol. 2006;1:18.

62. Ho EN, Chan GH, Wan TS, Curl P, Riggs CM, Hurley MJ, Sykes D. Control ling the misuse of cobalt in horses. Drug Test Anal. 2015;7(1):21-30. doi:10.1002/dta.1719 (Epub 2014 Sep 25)

63. Thevis M, Piper T, Geyer H, Thomas A, Schaefer MS, Kienbaum P, et al. Measuring xenon in human plasma and blood by gas chromatography/ mass spectrometry. Rapid Commun Mass Spectrom. 2014;28:1501-6.

64. Elliott S. Erythropoiesis-stimulating agents and other methods to enhance oxygen transport. Br J Pharmacol. 2008;154:529-41.

65. Torrance HD, Vivian ME, Brohi K, Prowle JR, Pearse RM, Owen HC, et al. Changes in gene expression following trauma are related to the age of transfused packed red blood cells. J Trauma Acute Care Surg. 2015;78:535-42.

66. Amato A, Pescatori M. Perioperative blood transfusions for the recurrence of colorectal cancer. Cochrane Database Syst Rev. 2006;CD005033.

67. Bernard AC, Davenport DL, Chang PK, Vaughan TB, Zwischenberger JB. Intraoperative transfusion of $1 \mathrm{U}$ to $2 \mathrm{U}$ packed red blood cells is associated with increased 30-day mortality, surgical-site infection, pneumonia, and sepsis in general surgery patients. J Am Coll Surg. 2009;208:931-937. e1-2 (discussion 938-9).

68. Long K, Woodward J, Procter L, Ward M, Meier C, Williams D, Bernard A. In vitro transfusion of red blood cells results in decreased cytokine production by human T cells. J Trauma Acute Care Surg. 2014;77:198-201.

69. Give blood -about blood. http://www.blood.co.uk/about-blood/. Accessed 27 Jul 15.

70. Carson JL, Sieber F, Cook DR, Hoover DR, Noveck H, Chaitman BR, et al. Liberal versus restrictive blood transfusion strategy: 3-year survival and cause of death results from the FOCUS randomised controlled trial. Lancet. 2015;385:1183-9.

71. Carson JL, Terrin ML, Noveck H, Sanders DW, Chaitman BR, Rhoads GG, et al. FOCUS Investigators: liberal or restrictive transfusion in high-risk patients after hip surgery. N Engl J Med. 2011;365:2453-62.

72. Murphy GJ, Pike K, Rogers CA, Wordsworth S, Stokes EA, Angelini GD, et al. TITRe2 investigators: liberal or restrictive transfusion after cardiac surgery. N Engl J Med. 2015:372:997-1008.

73. Villanueva C, Colomo A, Bosch A, Concepcion M, Hernandez-Gea V, Aracil $\mathrm{C}$, et al. Transfusion strategies for acute upper gastrointestinal bleeding. N Engl J Med. 2013;368:11-21.

74. Du Pont-Thibodeau G, Harrington K, Lacroix J. Anemia and red blood cell transfusion in critically ill cardiac patients. Ann Intensive Care. 2014;4:16. 
75. Holst LB, Haase N, Wetterslev J, Wernerman J, Guttormsen AB, Karlsson S, et al. Lower versus higher hemoglobin threshold for transfusion in septic shock. N Engl J Med. 2014;371:1381-91.

76. Hébert PC, Wells G, Blajchman MA, Marshall J, Martin C, Pagliarello G, et al. A multicenter, randomized, controlled clinical trial of transfusion requirements in critical care. transfusion requirements in critical care investigators, Canadian Critical Care Trials Group. N Engl J Med. 1999;340:409-17.

77. Lacroix J, Hébert PC, Fergusson DA, Tinmouth A, Cook DJ, Marshall JC, et al. Age of transfused blood in critically ill adults. N Engl J Med. 2015;372(15):1410-8.

78. Beal RW. The rational use of blood. Aust NZ J Surg. 1976;46:309-13.

79. Hung M, Ortmann E, Besser M, Martin-Cabrera P, Richards T, Ghosh M, et al. A prospective observational cohort study to identify the causes of anaemia and association with outcome in cardiac surgical patients. Heart. 2015;101:107-12.

80. National Blood transfusion Committee_-patient blood management an evidence-based approach to patient care. http://www.Transfusionguidelines.org.uk/uk-transfusion-committees/national-blood-transfusioncommittee/patient-blood-management. Accessed 01 Feb 2016.

81. Wright SE, Pearce B, Snowden CP, Anderson H, Wallis JP. Cardiopulmonary exercise testing before and after blood transfusion: a prospective clinical study. Br J Anaesth. 2014;113:91-6.

82. Ackland GL, labal S, Paredes LG, Toner A, Lyness C, Jenkins N, Bodger P, et al. POM-O (PostOperative Morbidity-Oxygen delivery) study group: individualised oxygen delivery targeted haemodynamic therapy in highrisk surgical patients: a multicentre, randomised, double-blind, controlled, mechanistic trial. Lancet Respir Med. 2015;3:33-41.

83. Jack S, West M, Grocott MP. Perioperative exercise training in elderly subjects. Best Pract Res Clin Anaesthesiol. 2011;25:461-72.

84. SantaMina D, Matthew AG, Hilton WJ, Au D, Awasthi R, Alibhai SM, et al. Prehabilitation for men undergoing radical prostatectomy: a multi-centre, pilot randomized controlled trial. BMC Surg. 2014;14:89.

85. Levett DZ, Grocott MP. Cardiopulmonary exercise testing, prehabilitation, and Enhanced Recovery After Surgery (ERAS). Can J Anaesth. 2015;62:131-42

86. Marinov BI, Terziyski KV, Sapunarova KG, Kostianev SS. Exercise performance in children with severe beta-thalassemia before and after transfusion. Folia Med (Plovdiv). 2008;50:48-54.
87. Pilot P, Bols EM, Verburg AD, Bell CA, Moonen AF, Van Os JJ, et al. The use of autologous blood to improve exercise capacity after total hip arthroplasty: a preliminary report. Transfusion. 2006;46:1484-90.

88. Preoperative intravenous iron to treat anaemia in major surgeryHome-PREVENTT Trial. http://preventt.Ishtm.ac.uk/. Accessed 27 Jul 2015.

89. Nielsen K, Johansson PI, Dahl B, Wagner M, Frausing B, Børglum J, Jensen K, Stürup J, Hvolris J, Rasmussen LS. Perioperative transfusion threshold and ambulation after hip revision surgery - a randomized trial. BMC Anesthesiol. 2014;14:89.

90. European Society of Anaesthesiology conference abstract June (2010) Foss NB: Peri-operative haemoglobin in the elderly: how low can we go? http://www.esahq.org/ /media/ESA/Files/Refresher\%20Courses/2010/ Peri-operative\%20haemoglobin\%20in\%20the\%20elderly\%20how\%20 low\%20can\%20we\%20go\%20(2010).ashx. Accessed 04 Feb 2016.

91. Jacobs RA, Flück D, Bonne TC, Bürgi S, Christensen PM, Toigo M, et al. Improvements in exercise performance with high-intensity interval training coincide with an increase in skeletal muscle mitochondrial content and function. J Appl Physiol. 2013;115:785-93.

92. Radak Z, Zhao Z, Koltai E, Ohno H, Atalay M. Oxygen consumption and usage during physical exercise: the balance between oxidative stress and ROS-dependent adaptive signaling. Antioxid Redox Signal. 2013;18:1208-46.

93. Silverman MN, Deuster PA. Biological mechanisms underlying the role of physical fitness in health and resilience. Interface Focus. 2014;4:20140040.

94. Gough CE, Eastwood A, Saunders PU, Anson JM, Gore CJ. Spurious Hb mass increases following exercise. Int J Sports Med. 2012;33:691-5.

95. Prommer N, Sottas PE, Schoch C, Schumacher YO, Schmidt W. Total hemoglobin mass-a new parameter to detect blood doping? Med Sci Sports Exerc. 2008;40:2112-8.

96. Garvican LA, Eastwood A, Martin DT, Ross ML, Gripper A, Gore CJ. Stability of hemoglobin mass during a 6-day UCI ProTour cycling race. Clin J Sport Med. 2010;20:200-4.

97. Schumacher YO, Garvican LA, Christian R, Lobigs LM, Qi J, Fan R, et al. High altitude, prolonged exercise, and the athlete biological passport. Drug Test Anal. 2014;7:48-55.

\section{Submit your next manuscript to BioMed Central and we will help you at every step:}

- We accept pre-submission inquiries

- Our selector tool helps you to find the most relevant journal

- We provide round the clock customer support

- Convenient online submission

- Thorough peer review

- Inclusion in PubMed and all major indexing services

- Maximum visibility for your research

Submit your manuscript at www.biomedcentral.com/submit

\section{() Biomed Central}

